Journal of Science
http://dergipark.gov.tr/gujs

\title{
Theoretical Determination of Corrosion Inhibitor Activities of Naphthalene and Tetralin
}

\author{
Rebaz Anwar OMER 1,*(D), Pelin KOPARIR ${ }^{2}$ (D) Ibrahim Nazem QADER ${ }^{\text {(D) }}$, Lana Omer AHMED ${ }^{4,5}$ \\ ${ }^{I}$ Department of Chemistry, Faculty of Science \& Health, Koya University, Koya KOY45, Kurdistan Region - F.R. Iraq \\ ${ }^{2}$ Department of Chemistry, Faculty of Science, Firat University, Elazig. Turkey \\ ${ }^{3}$ Department of Physics, College of Science, University of Raparin, Sulaymaneyah, Iraq \\ ${ }^{4}$ Department of Physics, Faculty of Science, Firat University, Elazig. Turkey \\ ${ }^{5}$ Department of Physics, Faculty of Science \& Health, Koya University, Koya KOY45, Kurdistan Region - F.R. Iraq
}

\section{Highlights}

- Inhibitor derivatives can be effective anti-corrosion agents.

- Organic corrosion inhibitory has a relationship with the quantum chemical parameters.

- The naphthalene molecule has the most beneficial corrosion inhibition impact compared to tetralin.

\section{Article Info}

Received: 28 Feb 2021

Accepted: 29 July 2021

Keywords

Naphthalene

Tetralin

DFT

Inhibitor activity

\begin{abstract}
Quantum mechanical methods were used to investigate the corrosion inhibitor activities of tetraline and naphthalene compounds. In this study, some parameters were estimated, including, the energy of the highest occupied molecular orbital (Еномо), the energy of the lowest occupied molecular orbital ( $\left.\mathrm{E}_{\mathrm{LUMO}}\right)$, the energy bandgap ( $\left.\Delta \mathrm{E}=\mathrm{E}_{\mathrm{LUMO}}-\mathrm{E}_{\mathrm{HOMO}}\right)$, and the dipole moment $(\mu)$. The aforementioned parameters give information about the corrosion efficiency of organic compounds. Furthermore, the density functional theory (DFT) was handled to determine the geometry of the molecules and electronic characteristics of the compounds. B3LYP/6-31G (d, p) was utilized to determine physical parameters such as hardness ( $\eta)$, softness $(\sigma)$, and electronegativity $(\chi)$. We also evaluated quantum chemistry characteristics including the fraction of electrons transported $(\Delta N)$ between the iron surface and our title compounds. This study also discusses which parameters have a significant linear relationship with inhibitory performance. The findings suggest that the behavior of organic-based corrosion inhibitors is correlated with the effectiveness of good corrosion inhibitors and the quantum chemical parameters measured from this process. As a result, the behavior of corrosion inhibitors can be determined without the need for an experiment.
\end{abstract}

\section{INTRODUCTION}

Naphthalene is made of two benzene rings bonded in ortho positions (Figure 1A). Naphthalene is colorless and possesses the odor of mothball and at room temperature, it can form a shiny flaked crystalline structure. At room temperature, it slowly sublimates and melted at $82.2^{\circ} \mathrm{C}$. Naphthalene is hydrophobic, while it can dissolve in alcohol and highly soluble in ether and benzene. It is very volatile and burns with a smoky flame [1]. There are some drugs containing naphthalene, such as nafcillin, naftifine, tolnaftate, and terbinafine [2], which play a crucial role in the management of microbial infections. Naphthalene mono hydroxide derivatives are called naphthol [3,4].<smiles>c1ccc2ccccc2c1</smiles>

naphthalene

A<smiles>c1ccc2c(c1)CCCC2</smiles>

1,2,3,4-tetrahydronaphthalene

B

Figure 1. Chemical structure for A) naphthalene B) tetralin 
Tetralin (1,2,3,4-tetrahydronaphthalene), on the other hand, is made up of two moiety: aromatic and alicyclic (Figure 1B). The chemical can be found in coal tar and petroleum, moreover, it can be made from naphthalene using catalytic hydrogenation or anthracene through cracking for industrial use. Tetralin compound is commonly used in the petrochemical industry as a solvent, where it is especially used in conjunction with liquefaction coal. It can be also used as an alternative for turpentine in each of paints and waxes [5]. Tetralin was increasingly degraded by mixed microorganism cultures [6] or by the presence of substrate [7].

Corrosion-preventive (inhibitor) characteristics are found in many organic compounds, and they have major economic implications [8]. Corrosion of metals, such as mild steel, causes many problems for various sectors. This condition can occur in several stages, especially during stages such as steel pickling, acid washing, and etching $[9,10]$. The corrosion inhibitors are a tiny number of chemical substances that prevent metal from corroding in harsh settings. These inhibitors are extensively employed in production industry for chemical cleaning solutions, industrial water, and petrochemical engineering because they are a costeffective and efficient way to prevent metal and alloy corrosion [11]. It can be stated that inhibitors act by altering the kinetics of electrochemical processes including the corrosion mechanism.

According to the available evidence, nealy all organic inhibitors function through adsorption on the metal surface. It is reported that the organic inhibitor molecules may usually adsorb onto metal and change physical or chemical properties [12]. Calculations based on quantum chemistry have shown to be a reliable tool for investigating corrosion inhibition mechanism [13] because significant associations were observed between the efficiencies of most compounds and vrious semi-empirical corrosion inhibition characteristics. The quantum chemical theory is a valuable method for predicting the inhibition capacity that are structurally related organic compounds [14-16].

The purpose of this research was to see how effective naphthalene and tetralin were at inhibitor activity. B3LYP/6-31G (d,p) was utilized to estimate structure of the molecules attributes of the aforementioned compounds. Molecular orbital computations are comonly ustilized to satisfy good theoretical parameters to identify inhibitors in order to understand the corrosion inhibition process and then to imitates the inhibitor adsorption method on the metal surface.

\section{CAlCUlation METHODS}

GaussView5.0, a molecular imaging tool, was used to map the three-dimensional form of the molecular compounds in the gas phase and the base case $[17,18]$. The GaussView 5.0 packet program was used to establish the starting geometries of the molecules, and the Gaussian09W software was used to perform the calculations $[19,20]$. Because the electron density is taken into consideration in the DFT approach, it can produce the needed data for a more accurate measurement of the electronic characteristics of compound structures [21,22]. DFT was also one of the first techniques to show a significant advantage against HartreeFock [23]. For various reasons, B3LYP is commonly used [24], which is faster than most techniques used for Post Hartree-Fock and usually yields comparable performance [21]. For a DFT process, it's also pretty robust. In addition, in the Gaussian09W program, the hybrid feature B3LYP is suited for the number of workstations and 6-31G G capacity (d, p) as the basis set [25]. From geometry-optimized structures, identifiers of electronic structures were found, and $\mathrm{E}_{\text {Hомо, }} \mathrm{E}_{\mathrm{LumO}}, \Delta \mathrm{E}, \sigma, \chi$, nucleophilicity $(\varepsilon)$ index, electrophilicity $(\omega)$ index, chemical potential $(\mathrm{Pi}), \mu$ and $\Delta \mathrm{N}$ linked to corrosion inhibitory action were estimated. Also, the identifier's electronic structure was investigated.

\section{RESULTS AND DISCUSSION}

\subsection{Geometry Optimization}

Table 1 lists the electronic structures and geometric properties, including the lengths of the bonds, bond angles, and dihedral angles of the naphthalene and tetralin inhibitors obtained in a gaseous phase. Figure 2 shows the molecular structures after optimization with calculated ground energies. B3LYP/6-31G(d,p) base sets were used to obtain sophisticated geometry improvements. 
Table 1. Some essential parameters, including bond length, Bond angle, and dihedral angle for both naphthalene and tetralin molecule

\begin{tabular}{|c|c|c|c|}
\hline \multicolumn{2}{|c|}{ Naphthalene } & \multicolumn{2}{|c|}{ Tetralin } \\
\hline Symbol & Bond Length & Symbol & Bond Length \\
\hline $\mathrm{C} 1-\mathrm{C} 2$ & 1.376307 & $\mathrm{C} 2-\mathrm{C} 1$ & 1.5267557 \\
\hline $\mathrm{C} 3-\mathrm{C} 2$ & 1.4210268 & $\mathrm{C} 3-\mathrm{C} 2$ & 1.5008836 \\
\hline C4-C3 & 1.433655 & C4-C3 & 1.4105343 \\
\hline $\mathrm{C} 5-\mathrm{C} 4$ & 1.4210387 & $\mathrm{C} 5-\mathrm{C} 4$ & 1.5008836 \\
\hline C6-C5 & 1.3763042 & C6-C1 & 1.4476828 \\
\hline H7-C3 & 2.1645062 & H7-C3 & 2.158854 \\
\hline H8-C1 & 1.0860828 & $\mathrm{H} 8-\mathrm{C} 1$ & 1.0813542 \\
\hline $\mathrm{H} 9-\mathrm{C} 2$ & 1.087031 & $\mathrm{H} 9-\mathrm{C} 2$ & 1.0849676 \\
\hline C10-C3 & 1.4210414 & C10-C3 & 1.3829612 \\
\hline C11-C4 & 1.421033 & C11-C4 & 1.3829612 \\
\hline H12-C5 & 1.0870321 & $\mathrm{H} 12-\mathrm{C} 5$ & 1.0849676 \\
\hline H13-C6 & 1.0860824 & H13-C6 & 1.0813542 \\
\hline C14-C11 & 1.3763034 & C14-C11 & 1.4076745 \\
\hline $\mathrm{C} 15-\mathrm{C} 10$ & 1.3763032 & C15-C14 & 1.392677 \\
\hline H16-C11 & 1.0870301 & H16-C11 & 1.0867578 \\
\hline H17-C14 & 1.0860836 & H17-C14 & 1.0862293 \\
\hline $\mathrm{H} 18-\mathrm{C} 15$ & 1.0860825 & $\mathrm{H} 18-\mathrm{C} 15$ & 1.0862293 \\
\hline Symbol & Bond angle & Symbol & Bond angle \\
\hline $\mathrm{C} 3-\mathrm{C} 2$ & 120.8679712 & $\mathrm{C} 3-\mathrm{C} 2-\mathrm{C} 1$ & 108.7644895 \\
\hline C4-C3-C2 & 118.8476397 & $\mathrm{C} 4-\mathrm{C} 3-\mathrm{C} 2$ & 104.6849883 \\
\hline $\mathrm{C} 5-\mathrm{C} 4-\mathrm{C} 3$ & 118.8454393 & C5-C4-C3 & 104.6849883 \\
\hline C6-C5-C4 & 120.8684748 & C6-C1-C5 & 61.7057142 \\
\hline H7-C3-C2 & 96.1731527 & H7-C3-C2 & 108.8794089 \\
\hline $\mathrm{H} 8-\mathrm{C} 1-\mathrm{C} 2$ & 120.1002612 & H8-C1-C6 & 135.2665001 \\
\hline H9-C2-C1 & 120.4211545 & H9-C2-C1 & 120.2338254 \\
\hline C10-C3-C2 & 122.3068893 & $\mathrm{C} 10-\mathrm{C} 3-\mathrm{C} 2$ & 134.320234 \\
\hline C11-C4-C3 & 118.8480087 & C11-C4-C3 & 120.9947768 \\
\hline H12-C5-C4 & 118.7104922 & H12-C5-C4 & 123.68896 \\
\hline H13-C6-C5 & 120.1004651 & H13-C6-C1 & 135.2665001 \\
\hline C14-C11-C4 & 120.8673684 & C14-C11-C4 & 118.1906017 \\
\hline C15-C10-C3 & 120.8679366 & C15-C14-C11 & 120.8146207 \\
\hline H16-C11-C4 & 118.7105053 & H16-C11-C4 & 121.4207727 \\
\hline H17-C14-C11 & 120.1010219 & H17-C14-C11 & 119.49422 \\
\hline H18-C15-C10 & 120.1003839 & H18-C15-C14 & 119.6911593 \\
\hline Symbol & dihedral angle & Symbol & dihedral angle \\
\hline C4-C3-C2-C1 & -0.0003329 & $\mathrm{C} 4-\mathrm{C} 3-\mathrm{C} 2-\mathrm{C} 1$ & 30.0525829 \\
\hline C5-C4-C3-C2 & 0 & C5-C4-C3-C2 & -0.0056504 \\
\hline C6-C5-C4-C3 & 0.0002866 & C6-C1-C5-C4 & 100.5365783 \\
\hline H7-C3-C2-C1 & 180 & H7-C3-C2-C1 & -149.9635128 \\
\hline H8-C1-C2-C3 & -179.9996731 & H8-C1-C6-C2 & 126.094165 \\
\hline H9-C2-C1-C6 & 180 & H9-C2-C1-C6 & 108.2771407 \\
\hline $\mathrm{C} 10-\mathrm{C} 3-\mathrm{C} 2-\mathrm{C} 1$ & 180 & C10-C3-C2-C1 & -149.9586165 \\
\hline
\end{tabular}




\begin{tabular}{|c|c|c|c|} 
C11-C4-C3-C2 & -180 & C11-C4-C3-C2 & -179.9963031 \\
\hline H12-C5-C4-C3 & 180 & H12-C5-C4-C3 & -179.9947554 \\
\hline H13-C6-C5-C4 & 179.9997201 & H13-C6-C1-C5 & 126.094165 \\
\hline C14-C11-C4-C3 & 0 & C14-C11-C4-C3 & -0.0069456 \\
\hline C15-C10-C3-C2 & -180 & C15-C14-C11-C4 & -0.0047713 \\
\hline H16-C11-C4-C3 & 180 & H16-C11-C4-C3 & 179.9765771 \\
\hline H17-C14-C11-C4 & -180 & H17-C14-C11-C4 & 179.9930536 \\
\hline H18-C15-C10-C3 & -180 & H18-C15-C14-C11 & -179.9870416 \\
\hline
\end{tabular}

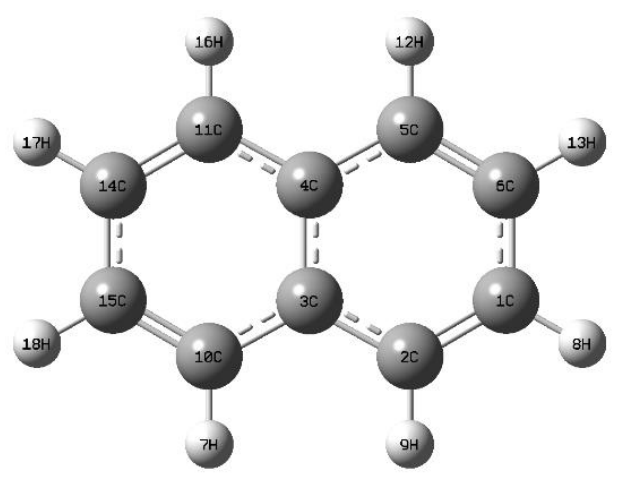

A

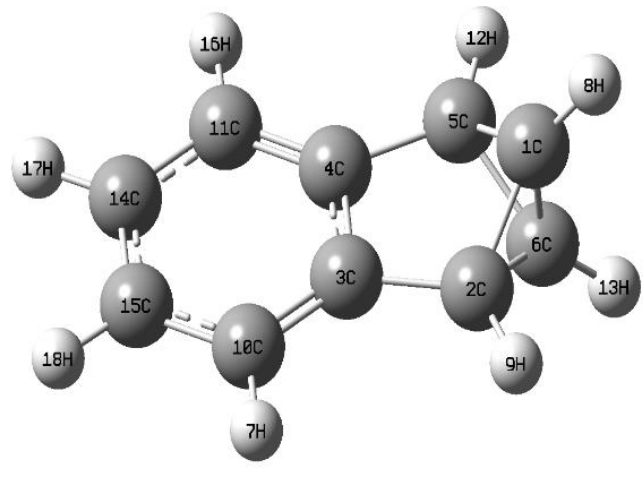

$\mathrm{B}$

Figure 2. The inhibitor compounds' was optimized; A) naphthalene; B) tetralin

\subsection{Inhibitor Parameters Activity}

The molecular electronic structure indicates the bond structure of the molecules and identifiers of the electronic structure. The corresponding electronic structural parameters, including $\mathrm{E}_{\text {номо, }} \mathrm{E}_{\mathrm{LumO}}, \Delta \mathrm{E}_{\mathrm{gap}}, \sigma$, $\chi, \mathrm{Pi}, \sigma, \chi, \varepsilon, \mu, \mathrm{HOMO}$, and LUMO were derived from the Gaussian outturn of the molecular profile. The energy level of the highest occupied and lowest unoccupied are defined as $\mathrm{E}_{\text {Hомо }}$ and $\mathrm{E}_{\mathrm{LUMO}}$, respectively, whereby their values determine the reactivity or passivity of a material. The following equations show the electron affinity (A) and the ionization potential (I) of the compounds:

$\mathrm{I}=-\mathrm{E}_{\mathrm{HOMO}}$

$\mathrm{A}=-\mathrm{E}_{\mathrm{LUMO}}$.

Calculate other identifies using equations was existed in the literature. Table 2 shows that there is a big difference between A and I value, moreover, the corresponding value of naphthalene are slightly more than tetralin. Additionally, ionization energy levels are linked to $\mathrm{E}_{\text {Номо }}$ and $\mathrm{E}_{\mathrm{Lumo}}$ values of any chemical type and electron affinity values, which were estimated according to Koopmans' theorem. Koopmans' theorem indicates that the negative energy of the HOMO equals the first ionization energy of a molecule [26, 27]. Normally inhibitors have a higher energy bandgap ( $\left.\mathrm{E}_{\mathrm{LUMO}}-\mathrm{E}_{\mathrm{HO} O}\right)$ compared to metallic materials. The energy bandgap $(\Delta \mathrm{E})$ of both inhibitors were calculated by the following equation:

$\Delta \mathrm{E}=\mathrm{E}_{\mathrm{LUMO}}-\mathrm{E}_{\text {Hомо }}$.

Atomic band structure achieves different properties when they bonded to other elements to make a compound. In this case, instead of atomic energy levels, we should deal with molecular orbitals, which are quite different from the components. The energy bandgap of naphthalene and tetralin are 4.823 and 5.579 $\mathrm{eV}$, which extremely higher than metallic materials, and they are listed in the insulator materials.

The hardness $(\eta)$ and $(\chi)$ inhibitor are theoretically determined through the equation: 
$\eta=(I-A) / 2$

and

$\chi=(\mathrm{I}+\mathrm{A}) / 2$

While Pearson experimentally calculates the $\chi$ and $\eta$ for the single atoms. The electron affinity (A) and ionization potential (I) of a single metal are supposed to be equal $(I=A)$, according to Pearson, the $\eta$ metal value for a single metal is assumed to be zero. In this study, we are used iron single metal $\chi$ equal to 7 and nzero.

The softness $(\sigma)$ and $(\mathrm{Pi})$ were respectively calculated by using the following equations [28-30]:

$\sigma=1 / \eta$

$\mathrm{Pi}=-\chi$

The electrophilicity $(\omega)$ and nucleophilicity $(\varepsilon)$ indexes are also related to the value of Pi and $\eta$ :

$\omega=\mathrm{Pi}^{2} / 2 \mathrm{\eta}$

$\varepsilon=\mathrm{Pi} . \eta$.

The electrophilicity index is the energy loss resulting from the entire electron flow between the transmitter and the receiver [31], whereas the new molecular structure identifier is the nucleophilicity index [23]. The following equation measures the $\Delta \mathrm{N}$ by using the theoretical values of $\chi$ and $\eta$, it is show the the electrons transferred between the inhibitor and the metal [8]:

$\Delta \mathrm{N}=\frac{(\chi \text { metal }-\chi \text { inhibitor })}{2(\eta \text { metal }-\eta \text { inhibitor })}$

Table 2. Identifiers electron structure calculated using B3LYP/6-31G(d,p) basis set

\begin{tabular}{llll}
\hline \hline \multirow{2}{*}{ Parameters } & & \multicolumn{1}{c}{ Molecule Name } \\
\cline { 3 - 4 } & & Naphthalene & Tetralin \\
\hline \hline Total Energy (a.u) & & -385.905 & -385.8 \\
$\mu(\mathrm{D})$ & 0 & 1.5713 \\
$\mathrm{E}_{\mathrm{HOMO}}(\mathrm{eV})$ & -5.802601584 & -5.788995784 \\
$\mathrm{E}_{\mathrm{LUMO}}(\mathrm{eV})$ & & -0.979345484 & -0.209257204 \\
$\Delta \mathrm{E}(\mathrm{eV})$ & $\Delta \mathrm{E}=\mathrm{E}_{\mathrm{HOMO}-\mathrm{E}_{\mathrm{LUMO}}}$ & -4.8232561 & -5.57973858 \\
$\mathrm{I}(\mathrm{eV})$ & $\mathrm{I}=-\mathrm{E}_{\mathrm{HOMO}}$ & 5.802601584 & 5.788995784 \\
$\mathrm{~A}(\mathrm{eV})$ & $\mathrm{A}=-\mathrm{E}_{\mathrm{LUMO}}$ & 0.979345484 & 0.209257204 \\
$\chi(\mathrm{eV})$ & $\chi=(\mathrm{I}+\mathrm{A}) / 2$ & 3.390973534 & 2.999126494 \\
$\eta(\mathrm{eV})$ & $\eta=(\mathrm{I}-\mathrm{A}) / 2$ & 2.41162805 & 2.78986929 \\
$\sigma(\mathrm{eV})$ & $\sigma=1 / \eta$ & 0.414657642 & 0.358439732 \\
$\mathrm{Pi}(\mathrm{eV})$ & $\mathrm{Pi}=-\chi$ & -3.390973534 & -2.999126494 \\
$\omega(\mathrm{eV})$ & $\omega=\mathrm{Pi}^{2} / \eta^{\wedge} 2$ & 1.977097775 & 1.155638107 \\
$\varepsilon(\mathrm{eV})$ & $\varepsilon=\mathrm{Pi}^{\prime} \eta$ & -8.177766891 & -8.367170902 \\
$\Delta \mathrm{N}$ & $\Delta \mathrm{N}$ & 0.748255202 & 0.717036013 \\
\hline \hline
\end{tabular}

Table 2 lists the electron structural descriptors for the compounds investigated. The energy values of HOMO and LUMO indicated that there is a general trend between the constructions studied. Since HOMO is connected to electron donating capacity, so it is critical in corrosion investigation. The HOMO of the 
naphthalene is greater than the tetralin. The inhibitory action of inhibitor compounds becomes stronger as HOMO values rise [32], therefore, the naphthalene shows a better inhibitor feature compared to tetralin. This characteristic enables inhibitory chemicals to work on the charge transfer process throughout the surface of the metal while also allowing them to withstand the adsorption process. Based on the high $\mathrm{E}_{\text {Номо }}$ value, the naphthalene molecule has the most potent inhibitor and the tetralin molecule possesses the lowest inhibitory activity (Figure 3).
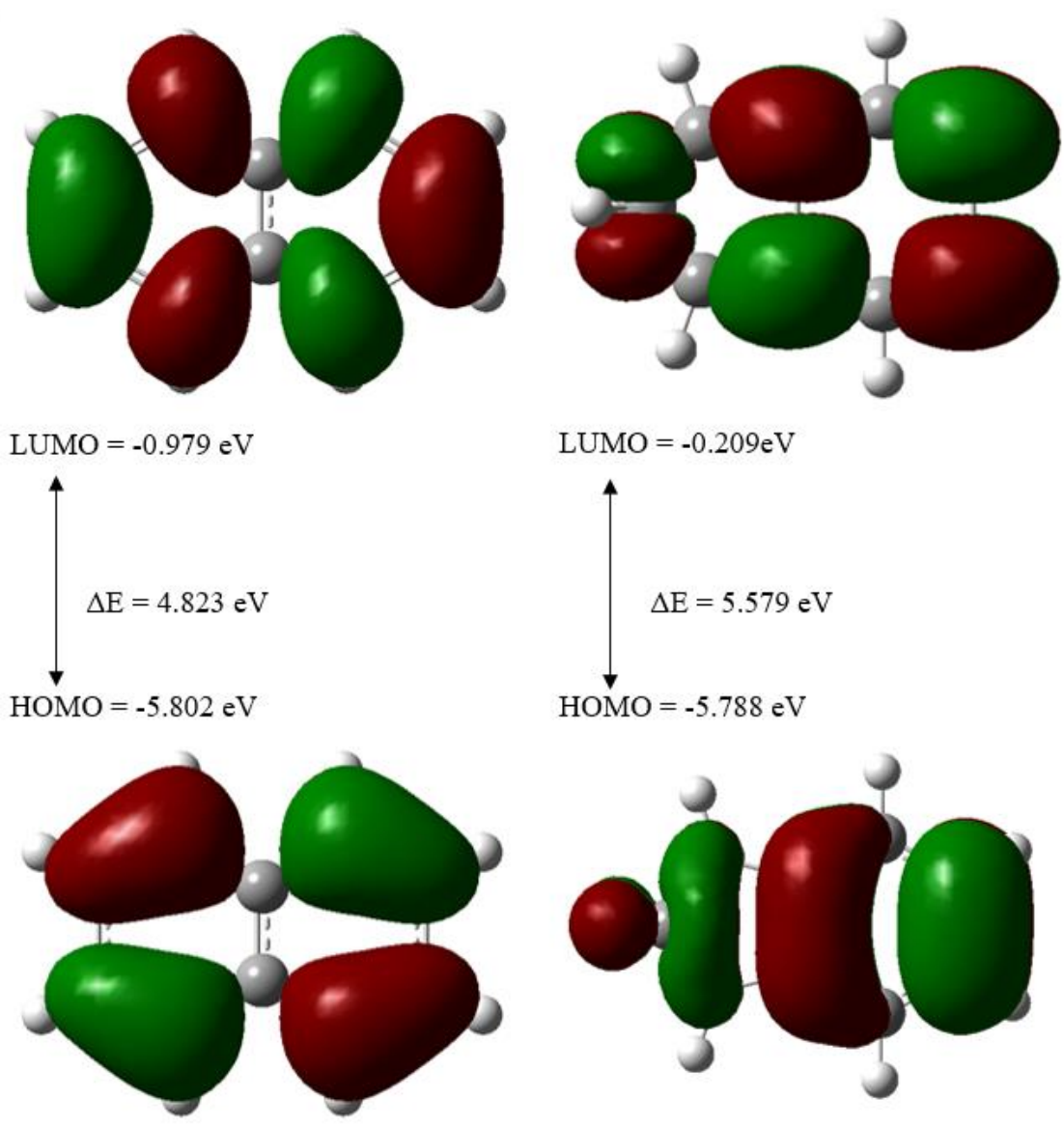

A

B

Figure 3. HOMO-LUMO and Energy bandgap of A) naphthalene B) tetralin

Because $\mathrm{E}_{\mathrm{LUMO}}$ has a low value, the inhibitor might charge the metal surface with a further negative charge. Tetralin LUMO energy possesses the lowest energy, whrease naphthalene has the highest value of LUMO energy. For this reason, the naphthalene molecule inhibitor was found to be reactive by acting as a donor. As a result, its inhibitory activity was high. The undermost values of $\mathrm{E}_{\mathrm{LUMO}}$ and $\mathrm{E}_{\text {Hомо }}$ are seen in the tetralin molecule inhibitor. Despite the fact that low- $\mathrm{E}_{\text {номо }}$ inhibitors diminish reactivity to metal inhibitors, the metal acts as a donor to the inhibitor. The inhibitor's action is reduced, while the metal's reactivity is boosted. The naphthalene molecule has the most powerful inhibition of corrosion based on energy band gaps (HOMO-LUMO).

For studying the inhibitor proficiency, it is necessary to compare the $\Delta \mathrm{E}$. The energy difference between $\mathrm{E}_{\text {номо }}$ and $\mathrm{E}_{\mathrm{Lumo}}$ has a lot of preliminary relevance and clarification when it comes to determining theoretical inhibitory effectiveness and static molecular reactivity. The energy bandgap for naphthalene is smaller than tetralin. The lower value of the energy bandgap, the greater the inhibition efficacy. The energy bandgap's value is determined by $\mathrm{E}_{\mathrm{HOMO}}$ instead of $\mathrm{E}_{\mathrm{LUMO}}$. With a high $\mathrm{HOMO}$ energy and low $\triangle \mathrm{E}$, inhibitor derivatives can be utilized as effective anti-corrosion agents [32]. According to the highest value of HOMO energy and the lowest value of $\Delta \mathrm{E}$, naphthalene will provide effective inhibitory action. Table 3 reveals that the charge distribution on the naphthalene and tetralin molecules. Mulliken population analysis (charge 
Distribution) is a commonly utilized technique for estimating inhibitor adsorption [32]. Many researchers have reported that the existence of negatively charged heteroatoms enhances the ability of donor-acceptor mechanisms to adsorb on the metal surface [33]. With this fact, naphthalene has an important inhibitory effect owing to a higher negative charge at the center of the molecule. Molecular electrostatic potential map (MEP) Figure 4 shows the charge distribution on the molecule by color. It is seen the center of the naphthalene molecule has denser red color than the tetralin molecular center, the is indicated that naphthalene more absorb on the surface of the metal.

Table 3. Charge distribution on the atoms for both naphthalene and tetralin

\begin{tabular}{|c|c|c|c|}
\hline \multicolumn{3}{|c|}{ Naphthalene } & \multicolumn{2}{c|}{ Tetralin } \\
\hline Atoms & Charge distribution & Atoms & Charge distribution \\
\hline C1 & -0.092621 & C1 & -0.0872 \\
\hline C2 & -0.128589 & C2 & -0.21306 \\
\hline C3 & 0.101945 & C3 & 0.104271 \\
\hline C4 & 0.102287 & C4 & 0.104271 \\
\hline C5 & -0.128295 & C5 & -0.21306 \\
\hline C6 & -0.09298 & C6 & -0.0872 \\
\hline H7 & 0.084669 & H7 & 0.088095 \\
\hline H8 & 0.085517 & H8 & 0.108209 \\
\hline H9 10 & 0.084611 & H9 & 0.138355 \\
\hline C11 & -0.128213 & C10 & -0.12439 \\
\hline H12 & -0.128707 & C11 & -0.12439 \\
\hline H13 & 0.084744 & H12 & 0.138355 \\
\hline C14 & 0.085556 & H13 & 0.108209 \\
\hline C15 & -0.092621 & C14 & -0.0942 \\
\hline H16 & -0.092937 & C15 & -0.0942 \\
\hline H17 & 0.084528 & H16 & 0.088095 \\
\hline H18 & 0.085522 & H17 & 0.079917 \\
\hline
\end{tabular}

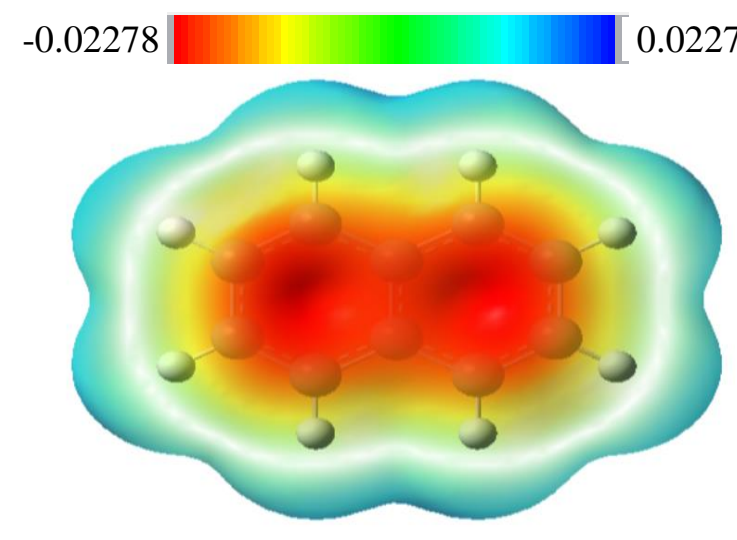

A

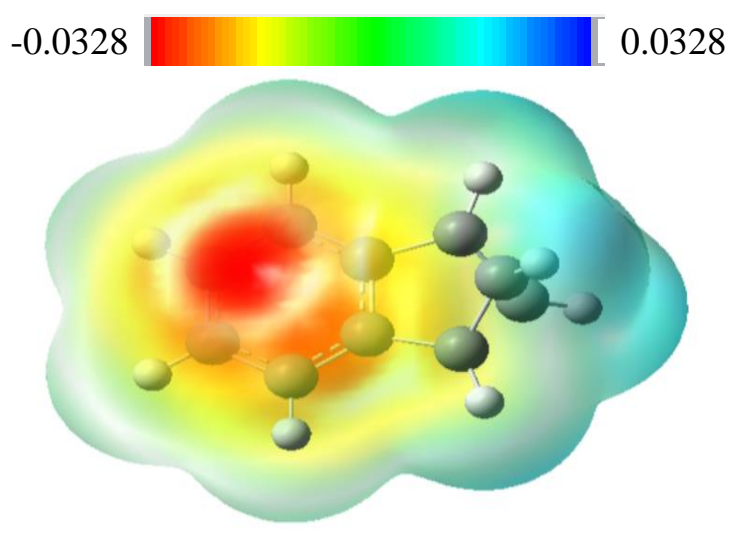

B

Figure 4. Molecular electrostatic potential map A) naphthalene B) tetralin

Other significant parameters that provide information on the stability, reactivity, and inhibitor activity of the inhibitor molecules are hardness and softness. The hardness ( $\eta$ ) of naphthalene is less than tetralin, while the softness $(\sigma)$ of tetralin is lower than naphthalene. Because the organic inhibitor chosen is Lewisbased, and soft inhibitors are more reactive than hard inhibitors, they act as more effective corrosion inhibitors [34-36]. Therefore, for this situation, the naphthalene inhibitor with high EHOMO and low $\Delta \mathrm{E}$ was shown to have high softness and low hardness scores. 
Additionally, $\chi$ and Pi are to important parameters, which were calculated to determine and compare the inhibitor activity of the compounds. The calculated values of the $\chi$ provide details about how the coordinated covalent bond happens between the metal and the inhibitor. In the current investigation, iron metal was used for examined our molecular inhibitor activity. It is found that the $\chi$ values of the inhibitors (Table 2) are smaller compared to the corresponding reported value for the iron metal. The iron metal was take electrons from the inhibitor compound to form bonds. Also, naphthalene was shown higher inhibitor reactivity with a lower $\chi$ value. The $\Delta \mathrm{N}$ values for iron and metal inhibitors were obtained (Table 2) show that the naphthalene molecule can transfer more electrons to the iron metal that makes it a more powerful inhibitor.

Although there is no studies mentioned the direct correlation between dipole moment $(\mu)$ and the activity of inhibition, in some studies, the behavior of molecules with a higher $\mu$ have been determined as a good inhibition, whereas in other studies, the inhibition activity increase with a decrease in $\mu$ value. There is a low dipole moment in the naphthalene inhibitor, which is in line with other parameters. This can be translated at low $\mu$ values as a stronger coating of the metal surface.

The $\omega$ and $\varepsilon$ indices are major features employed in the operations of inhibitors. Additionally, the $\omega$ index shows the inhibitor molecules' ability to admit electrons, whereas the $\varepsilon$ index indicates the inhibitors' capacity to donate electrons $[23,31]$. The activity of inhibition rises as the $\varepsilon$ value decreases or the $\omega$ value increases. Naphthalene molecule has a lower value for $\varepsilon$ and a higher value for $\omega$ which is opposite to tetralin molecule. It is noted that, according to $\omega$ and $\varepsilon$ features, the naphthalene inhibitor possesses the highest powerful inhibitory effect.

\section{CONCLUSION}

In this study, the inhibitory of naphthalene and tetralin compounds were studied theoretically using the Gaussian package program. According to the results, the $\mathrm{E}_{\text {Hомо }}$ and $\mathrm{E}_{\mathrm{LUMO}}$ of the inhibitor molecules have a higher value, also it is found that naphthalene inhibitor was more reactive compared to tetralin by taking on the role of a donor. With high $\mathrm{E}_{\text {номо }}$ and low $\Delta \mathrm{E}$, inhibitor derivatives can be utilized as good anticorrosion agents. Based on the obtained results of $\mathrm{E}_{\mathrm{HOMO}}$ and $\Delta \mathrm{E}$, naphthalene has greatest value of $\mathrm{E}_{\mathrm{HO} о}$, there is a substantial inhibitory activity. The Mulliken atomic charges of naphthalene showed that the inhibitory action is influenced significantly by electronegative of atoms. It is possible to connect the negatively charged atoms at the centers of the naphthalene molecule to the metal surface. When compared to tetralin, the determined $\eta, \sigma, \chi, \mathrm{Pi}, \omega$, and $\varepsilon$ parameters support the naphthalene molecule having the maximum effective corrosion inhibition impact. The higher $\chi$ value of the inhibitor the more likely the iron metal forms a bond by stealing electrons from the inhibitor's molecule, and so $\Delta \mathrm{N}$ can have the maximum value. Consequently, there is a near connection between the organic corrosion inhibitory with the quantum chemical parameters obtained for the compounds.

\section{CONFLICTS OF INTEREST}

No conflict of interest was declared by the authors.

\section{REFERENCES}

[1] Rokade, Y., and Sayyed, R., "Naphthalene derivatives: A new range of antimicrobials with high therapeutic value", Rasayan Journal of Chemistry, 2(4): 972-980, (2009).

[2] Ersan, R. H., Yuksel, A., Ertan-Bolelli,, T., Dogen, A., Burmaoglu S., and Algul, O., "One-pot synthesis of novel benzimidazoles with a naphthalene moiety as antimicrobial agents and molecular docking studies", Journal of the Chinese Chemical Society, 68(2): 374-383, (2021).

[3] Wilson, C. O., Gisvold, O., Block, J. H., and Beale, J. M., Wilson and Gisvold's textbook of organic medicinal and pharmaceutical chemistry/edited by John H. Block, John M. Beale Jr., (2004). 
[4] Doerge, R. F., Wilson and Gisvold's textbook of organic, medicinal and pharmaceutical chemistry, Lippincott, 8th edition, (1982).

[5] Sikkema, J., and de Bont, J., "Metabolism of tetralin (1, 2, 3, 4-tetrahydronaphthalene) in Corynebacterium sp. strain C125", Applied and Environmental Microbiology, 59(2): 567-572, (1993).

[6] Strawinski, R., and Stone, R., "The utilization of hydrocarbons by bacteria", Journal of Bacteriology, 40: 461-462, (1940).

[7] Jamison, V., Raymond, R., and Hudson, J., "Hydrocarbon cooxidation by Nocardia corallina strain V-49", Developments in Industrial Microbiology, 12: 99-105, (1971).

[8] Musa, A. Y., Jalgham, R. T., and Mohamad, A. B., "Molecular dynamic and quantum chemical calculations for phthalazine derivatives as corrosion inhibitors of mild steel in $1 \mathrm{M} \mathrm{HCl}$ ", Corrosion Science, 56: 176-183, (2012).

[9] Revie, R. W., Corrosion and corrosion control: an introduction to corrosion science and engineering, 4th Edition, John Wiley \& Sons, New Jersey, (2008).

[10] Eddy, N. O., and Ita, B. I., "QSAR, DFT and quantum chemical studies on the inhibition potentials of some carbozones for the corrosion of mild steel in $\mathrm{HCl} "$, Journal of Molecular Modeling, 17(2): 359-376, (2011).

[11] Issa, R. M., Awad, M. K., and Atlam, F. M., "Quantum chemical studies on the inhibition of corrosion of copper surface by substituted uracils", Applied Surface Science, 255(5): 2433-2441, (2008).

[12] Singh, A. K., and Quraishi, M., "The effect of some bis-thiadiazole derivatives on the corrosion of mild steel in hydrochloric acid", Corrosion Science, 52(4): 1373-1385, (2010).

[13] Tang, Y.M. Chen, Y., Yang, W. Z., Liu, Y., Yin, X.S., and Wang, J.T., "Electrochemical and theoretical studies of thienyl-substituted amino triazoles on corrosion inhibition of copper in 0.5 MH 2 SO 4", Journal of Applied Electrochemistry, 38(11): 1553-1559, (2008).

[14] Gece G., and Bilgiç S., "Quantum chemical study of some cyclic nitrogen compounds as corrosion inhibitors of steel in NaCl media", Corrosion Science, 51(8): 1876-1878, (2009).

[15] Bereket, G., Hür, E., and Öğretir, C., "Quantum chemical studies on some imidazole derivatives as corrosion inhibitors for iron in acidic medium", Journal of Molecular Structure: Theochem, 578(13): 79-88, (2002).

[16] Zhang, S., Lei, W., Xia, M., and Wang, F., "QSAR study on N-containing corrosion inhibitors: quantum chemical approach assisted by topological index", Journal of Molecular Structure: Theochem, 732(1-3): 173-182, (2005).

[17] Dennington, R., Keith, T. and Millam, J. G., "Version 5", Semichem Inc.: Shawnee Mission, KS, USA, (2009).

[18] Rebaz, O., Koparir, P., Ahmed, L.,, and Koparir, M., "Computational determination the reactivity of salbutamol and propranolol drugs", Turkish Computational and Theoretical Chemistry, 4(2): 67$75,(2020)$.

[19] Foresman, J., and Frish, E., "Exploring chemistry", Gaussian Inc., Pittsburg, USA, (1996). 
[20] Ahmed, L., and Rebaz, O., "Spectroscopic properties of Vitamin C: A theoretical work", Cumhuriyet Science Journal, 41(4): 916-928, (2020).

[21] Ahmed, L., and Rebaz, O., "A theoretical study on Dopamine molecule", Journal of Physical Chemistry and Functional Materials, 2(2): 66-72, (2019).

[22] İbişoğlu, H., Atilla, D., Tümay, S. O., Şenocak,, A., Duygulu, E., and Yuksel, F., "New cyclotriphosphazene ligand containing imidazole rings and its one-dimensional copper (II) coordination polymer", Journal of Molecular Structure, 1208: 127888, (2020).

[23] Pearson, R. G., "Absolute electronegativity and hardness: application to inorganic chemistry", Inorganic Chemistry, 27(4): 734-740, (1988).

[24] Aydogmus, Z., Aslan, S. S., Yildiz, G., and Senocak, A., "Differential Pulse Voltammetric Determination of Anticancer Drug Regorafenib at a Carbon Paste Electrode: Electrochemical Study and Density Functional Theory Computations", Journal of Analytical Chemistry, 75(5): 691-700, (2020).

[25] Becke, A. D., "Density-functional thermochemistry. IV. A new dynamical correlation functional and implications for exact-exchange mixing", The Journal of Chemical Physics, 104(3): 10401046, (1996).

[26] Plakhutin, B. N., and Davidson, E. R., "Koopmans' Theorem in the Restricted Open-Shell HartreeFock Method. 1. A Variational Approach", The Journal of Physical Chemistry A, 113(45): 1238612395, (2009).

[27] Koopmans, T., "Über die Zuordnung von Wellenfunktionen und Eigenwerten zu den einzelnen Elektronen eines Atoms", Physica, 1(1-6): 104-113, (1934).

[28] Jesudason, E. P., Sridhar, S., Malar, E. P., Shanmugapandiyan, P., Inayathullah, M., Arul, V., Selvaraj, D. and Jayakumar, R., "Synthesis, pharmacological screening, quantum chemical and in vitro permeability studies of N-Mannich bases of benzimidazoles through bovine cornea", European Journal of Medicinal Chemistry, 44(5): 2307-2312, (2009).

[29] Gökce, H., and Bahceli, S., "A study on quantum chemical calculations of 3-, 4-nitrobenzaldehyde oximes", Spectrochimica Acta Part A: Molecular and Biomolecular Spectroscopy, 79(5): 17831793, (2011).

[30] Arivazhagan, M., and Subhasini, V., "Quantum chemical studies on structure of 2-amino-5nitropyrimidine", Spectrochimica Acta Part A: Molecular and Biomolecular Spectroscopy, 91: 402-410, (2012).

[31] Kiyooka, S. I., Kaneno, D., and Fujiyama, R., "Parr's index to describe both electrophilicity and nucleophilicity", Tetrahedron Letters, 54(4): 339-342, (2013).

[32] Chen, S., He, B., Liu, Y., Wang, Y. and Zhu, J., "Quantum chemical study of some benzimidazole and its derivatives as corrosion mhibitors of steel in $\mathrm{HCl}$ solution", International Journal of Electrochemical Science, 9: 5400-5408, (2014).

[33] El Adnani, Z., Mcharfi, M., Sfaira, M., Benzakour, M., Benjelloun, A., and Touhami, M. E., "DFT theoretical study of 7-R-3methylquinoxalin-2 (1H)-thiones (RH; CH3; Cl) as corrosion inhibitors in hydrochloric acid", Corrosion Science, 68: 223-230, (2013). 
[34] Fujioka, E., Nishihara, H., and Aramaki, K., "The inhibition of pit nucleation and growth on the passive surface of iron in a borate buffer solution containing $\mathrm{Cl}-$ by oxidizing inhibitors", Corrosion Science, 38(11): 1915-1933, (1996).

[35] Koch, E. C., "Acid-Base Interactions in Energetic Materials: I. The Hard and Soft Acids and Bases (HSAB) Principle-Insights to Reactivity and Sensitivity of Energetic Materials", Propellants, Explosives, Pyrotechnics: An International Journal Dealing with Scientific and Technological Aspects of Energetic Materials, 30(1): 5-16, (2005).

[36] Alexander, D., and Moccari, A., "Evaluation of corrosion inhibitors for component cooling water systems", Corrosion, 49(11): 921-928, (1993). 